\title{
Geochemical characteristics of bottom sediments of Lake Onega
}

\author{
E.I. Valieva ${ }^{1}$, E.N. Poludetkina ${ }^{1}, O . N$. Vidishcheva $^{1}$, A.K. Mirinets ${ }^{1}$, and A.E. Rybalko ${ }^{2}$ \\ ${ }^{1}$ Lomonosov Moscow State University, Moscow, Russia \\ ${ }^{2}$ Institute of Earth Sciences, St. Petersburg State University, St. Petersburg, Russia
}

\begin{abstract}
The subject of this article represents results of scientific studies in 2018-2019. The studies indicate that the phenomena of gas saturation of bottom sediments are often observed within the Lake Onega. Basically, this occurs in the mouths, while in the open part of the lake the degree of gas saturation of the sediments is incomparably less. According to the geochemical studies, numerous signs confirmed the predominantly biogenic origin of gases.
\end{abstract}

\section{Introduction}

At present, the problem of gases in the bottom sediments offshore is relevant and scientifically important in at least two aspects:

- accumulations of gases in the bottom sediments form zones of abnormally high reservoir pressure (APRD), which pose a real danger during offshore exploration work, as well as for production wells;

- the use of gases in the process of gas-geochemical surveys at the exploration stage of hydrocarbon development.

Currently, in multiple offshore objects, including the North-West of Russia, such as the Barents, White, Kara and Baltic Seas, numerous gas-geochemical studies have been carried out, the methodology of such works has been worked out, and important scientific and practical results have been obtained by multiple scientific groups [1-11]. At the same time, until recently, such work has not been carried out at all on the Great Lakes of Europe: Ladoga and Onega. This was largely due to a sharp restriction in the possibilities of conducting offshore geological exploration due to the threat of even minimal pollution, because the lakes themselves are, in essence, the most important strategic reserve of drinking water, including that for the largest cities: St. Petersburg, Petrozavodsk and others.

The problem of gases in the bottom sediments of Lake Onega, in essence, began in 2015, when pockmarks (funnel-shaped structures formed as a result of the outflow of gases from the bottom sediments) were for the first time identified during the geophysical equipment tuning works in the Petrozavodsk Bay before the departure of the research vessel "Ekolog" to Lake Ladoga. Exactly the same pockmarks were identified during the already mentioned tuning works in 2015, almost opposite the city of Petrozavodsk [12].

In 2016 complex geological and geophysical work was carried out in the Petrozavodsk Bay, to develop a methodology for studying the geological structure of offshore basins using the polygon method and methodology for conducting certain types of work included in 
the set of geotechnical surveys. This included a gas-geochemical survey with resulting identification of numerous gas manifestations, including coring of obvious signs of gas emanations and numerous pockmarks within the mouth zones [13]. For the first time, tomographic studies were performed in MSU for all internal basins of the North-West of Russia, which made it possible to characterize in detail the texture features of Late Quaternary sediments, including documenting the features of gas manifestations in the clayey sediments (Figure 1).

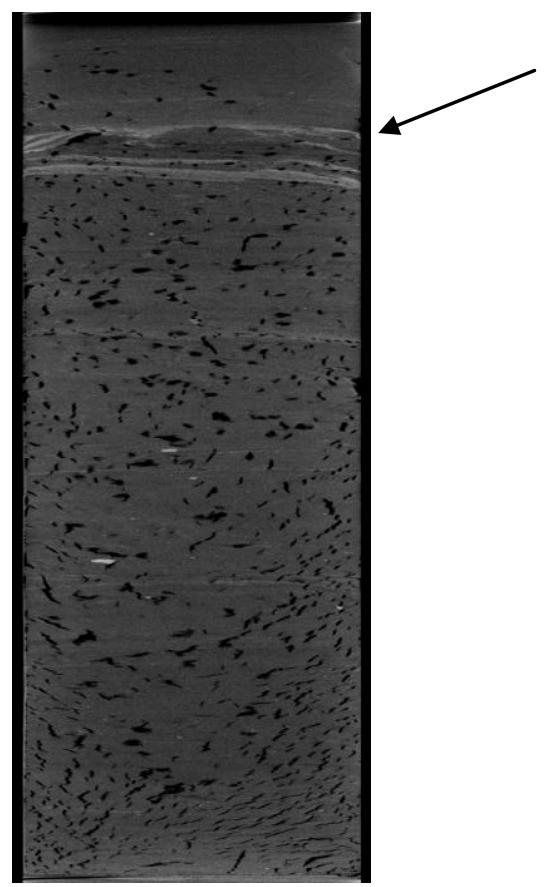

Fig. 1. Tomography of a vertical section of the ONG-2016-8 tube from Onega Bay. Pores saturated with gas are clearly visible. Their orientation indicates the movement of dissolved gases up the section. A distinct erosive contact (arrow) is visible in the upper part of the section, which partially screens the movement of gases to the surface of the seabed.

These works were continued, including with the aim of creating a map of the Quaternary deposits of Lake Onega and the characteristics of its evolution in Late Pleistocene-Holocene in its open part. Compared with the reference polygon studies the work in the Petrozavodsk Bay in 2016-2019 was carried out according to the reduced program and included seismic-acoustic profiling. The results of the work in 2018-2019 are the subject of this article.

\section{Materials and methodology}

Fieldworks in 2018-2019 were held jointly with Marine Research Centre, MSU, with the participation of the Lomonosov Moscow State University, the Institute of Earth Sciences of St. Petersburg State University, Northern Water Problems Institute (NWPI), Karelian Research Centre RAS, and Herzen State Pedagogical University of Russia. All studies were carried out from the R/V "Geoekolog", owned by the NWPI RAS.

Geological work was carried out using a gravity core with a length of $3 \mathrm{~m}$ diameter of $127 \mathrm{~mm}$ with a total weight of $300 \mathrm{~kg}$. All stations were preplanned according to the preliminary interpretation of seismoacoustic profiling. The choice of sampling points was 
determined by the following factors: stations were selected both in the areas of the most intense Holocene nepheloid sedimentation and in the areas of the underlying sediments outcropping. Separately, points with visible signs of gas seepage in Holocene sediments were selected.

The selected points run to increase the accuracy of sampling was carried out at a drift, taking into account wind direction. The drift of the vessel was monitored by the vessel GPS system; the gravity core was dropped when the ship crossed the intended point. In shallow water (depths up to 50m) sampling was carried out at anchor.

Work was carried out from the aft winch. The gravity core round trip from the deck was carried out using a ship crane. The measurement accuracy did not exceed $\pm 10 \mathrm{~m}$, although this was sufficient, since all stations were cored for the first time. After the hoisting operation, the core was laid out along the side and the sediment was extruded. Two iterations were fulfilled for each station. The first core (core sampling in the pipe was carried out in plastic liners) was unsealed and used for further documentation and sampling, including for gases. The second core was cut into $1 \mathrm{~m}$ sections and remained in plastic liners prepared for transportation to the laboratories of Moscow or St. Petersburg.

In 2018 and 2019, the studies were carried out at 18 sites (Figure 2), 34 cores with a total length of $65 \mathrm{~m}$ were selected and described. In 2018, the work was carried out in the open part of the lake, with the main task of mapping the Quaternary sediments and identifying the boundaries between lacustrine Holocene nepheloid silt sediments and Neopleistocene glacial-lacustrine clays. In 2019, the main task of geological sampling was to find out the geological structure of the Quaternary cover in the Bolshoy Onega Bay and to identify the gas contamination of bottom sediments in the northern river mouth of the Onega Bay.

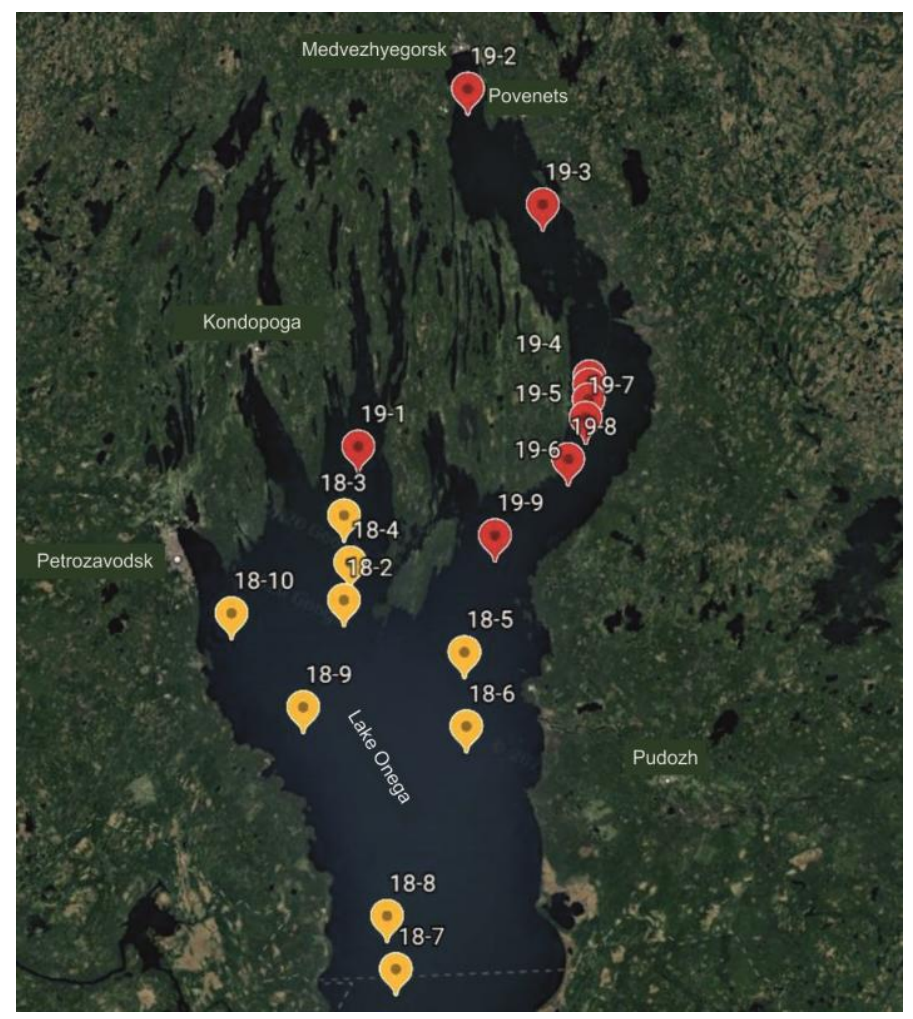

Fig. 2. Well location map, 2018-2019. 


\section{Geological structure}

The main features of the Quaternary sediments geology were established according to the results of studies in 2016 and confirmed as a result of ice drilling in the Petrozavodsk Bay in spring 2019 [14]. In general, the section is a glaciation sedimentation cycle of the last Ostashkovsky glaciation and includes (from top to bottom):

- $\ln _{3}$. The horizon is represented by clayey silt, the color of which in different columns varies from greenish-brown to olive-gray. Clusters of dark grey to black manganese hydroxides are observed. Down the interval there is an increase in sand particles. In the columns where contact with the underlying layer was noted, the contact is described as erosive (Figure 1), emphasized by the layers of sand material.

- $\ln \mathrm{H}_{3-2}$. The horizon is represented in various cores by clayey silt, silty clay or clay, with the predominance of the latter. The color is predominantly gray, there are slight contractions of manganese hydroxides in the lower part of the section.

- $\ln \mathrm{H}_{2}$. The horizon is represented by gray silty clays, with fuzzy diagenetic zoning, with thin bands formed by manganese hydroxides.

- $\ln \mathrm{H}_{1}$. The horizon is represented by homogeneous silty clays and clays of ash-gray color, sometimes with an olive tint. Sandy inclusions of presumably authigenic sulfides are observed.

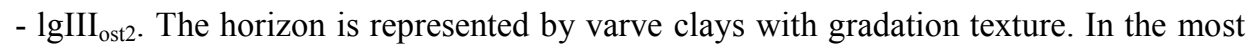
complete sections, it seems possible to distinguish three subhorizons within this horizon, the upper of which is represented by micro-varve clays, the middle one is highlighted by an increase in the cycles thickness, and the lower one is underlined by color (beige tone). Moreover, this horizon is marked out by a layer of so-called "pink" clays, the genetic nature of which has not yet been clarified.

$\operatorname{lgIII} \mathrm{ostl}_{1}$. The horizon is represented by gray varve clays with irregular color cyclic layering. Probably these are distal clays.

According to drilling data, thick-layered (proximal) varve clays and glacial and fluvioglacial formations of the last glaciation lie at the base of these layers. From the point of view of gas sampling, the top 4 layers are of primary interest, although this does not exclude the inflow of gases through varve clays.

A separate problem that was solved in the course of the work carried out was the possible gas content of bottom sediments in the river mouth of the northern part of the Onega Bay, where intensive sedimentation of Holocene clay nepheloid deposits occurs within a rather limited area. The sedimentation conditions recall lacustrine ones that occur in small lakes due to the intensive supply of organic material from the onshore, and the formation of the bays is associated with neotectonic processes. At that numerous seismic dislocations indicate the possibility of seismogenic phenomena in Late Holocene.

Geological sampling performed in 2019 showed that in the significant part of Zaonezhsky Bay, the easternmost and longest of the northern bays of Lake Onega, Holocene nepheloid ooze are widely developed. They fill both the northern part of this bay near the city of Medvezhyegorsk, and the southern, open to the central part of the lake. Here, in the south, the bottom sediments showed macro-signs of gas saturation - "boiling" of the core with the formation of bubbles. Computed tomography data confirmed the field studies. 


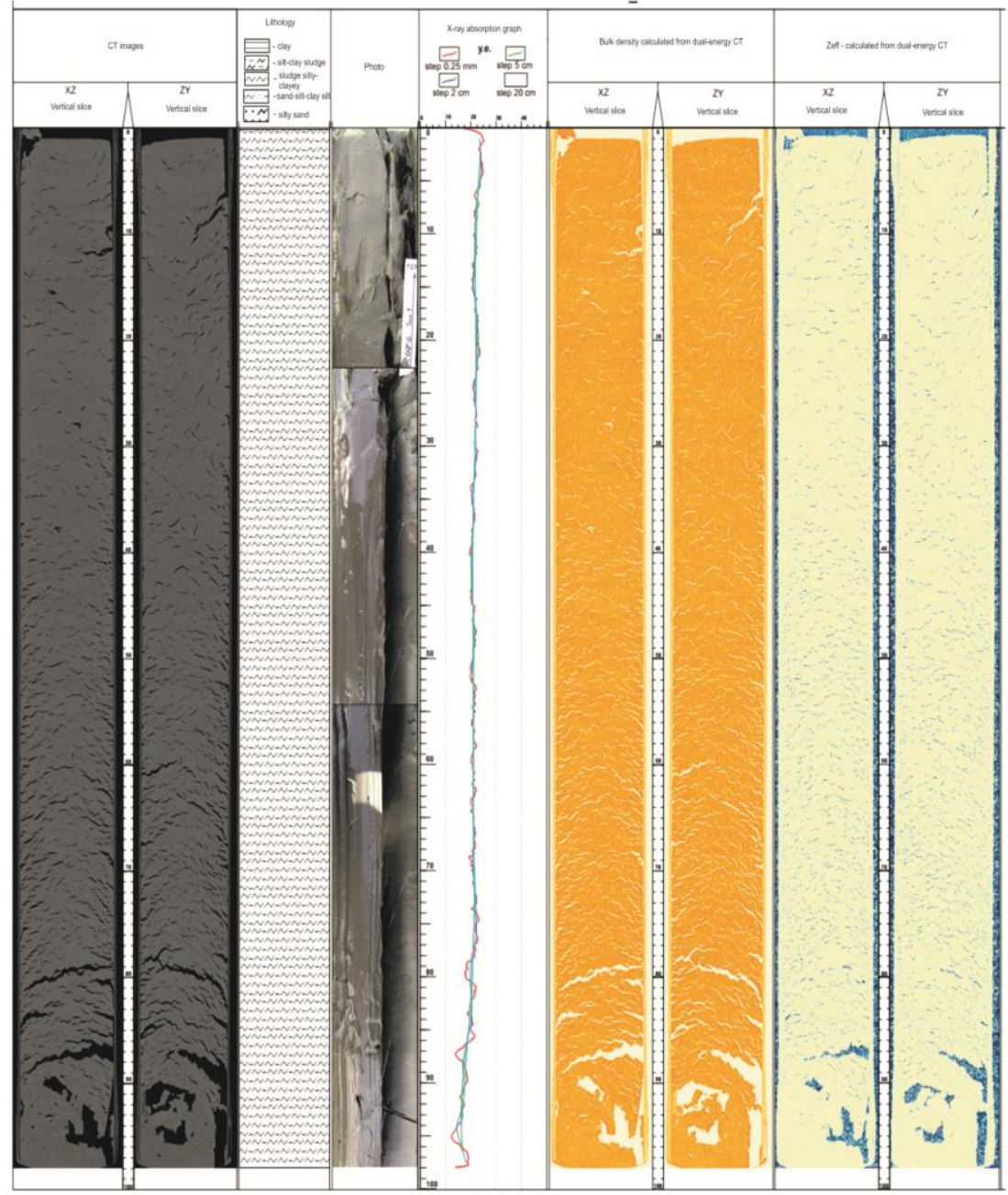

Fig. 3. Computer tomogram of the upper section, station 19-7 (location - see Figure 2).

The entire section represents $\ln H$. Materials of MRC MSU

Computer tomography shows visible high porosity of the ooze in their upper part. The pores themselves are located along the bedding, at the same time raised upward, which indicates the tendency of gases upwards the core.

\section{Geochemical studies}

The geochemical studies included sampling and analysis of 56 samples of bottom sediments for organic matter and 56 gas samples studies. Samples were taken from each core in different lithological types. Sampling for bituminological studies was carried out from the same intervals. Sampling was fulfilled into sealed bags with a further fluorescent analysis that was performed in the laboratories of Moscow State University.

The gas-phase was extracted using degassing according to the "Head space" method. The main feature of this method is the establishment of a state of phase equilibrium between the gas and water phases under Henry's law (Figure 4). Afterward the gas phase was studied on a gas chromatograph "Gasochrom-2000". 

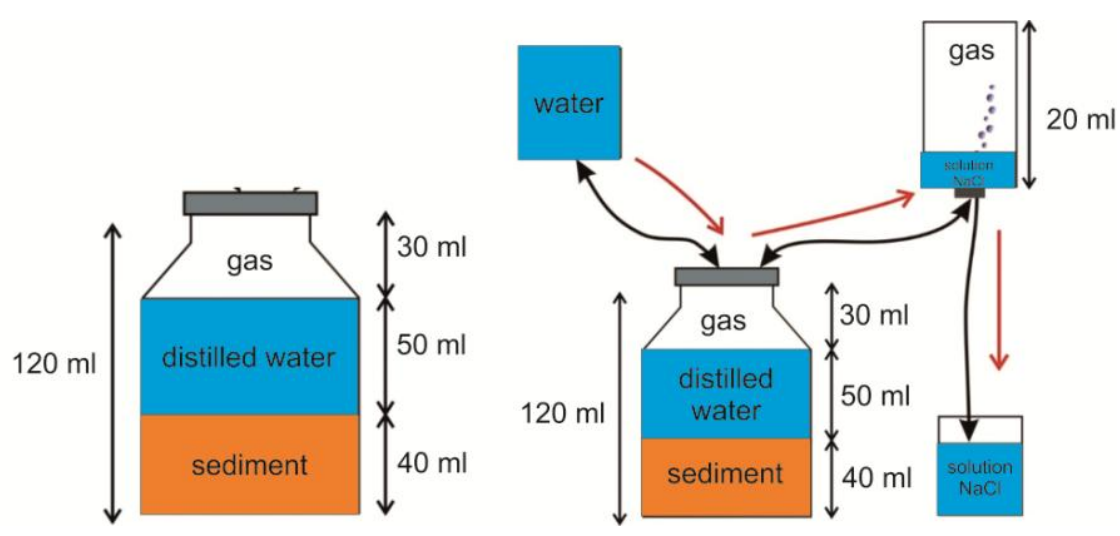

Fig. 4. Standard degassing method of bottom sediments for subsequent chromatographic analysis of the gas phase.

The gas contains hydrocarbons (HCs), mainly methane, the volumetric content of which in the gas mixture reaches $16.1 \%$ (stations $19-7,18-3,18-4$ ). In general, the gas content increases with the depth, reaching maximum concentrations (12-16,1 vol.\%) at depths of more than $150 \mathrm{~cm}$. HC concentrations are minimal at a depth of less than $50 \mathrm{~cm}$ (less than 2 vol.\%). Methane homologues concentrations are low or not detected due to liquefaction of the sediment that leads to minimizing of the absorption effect as well as active bacterial activity (Figure 5).

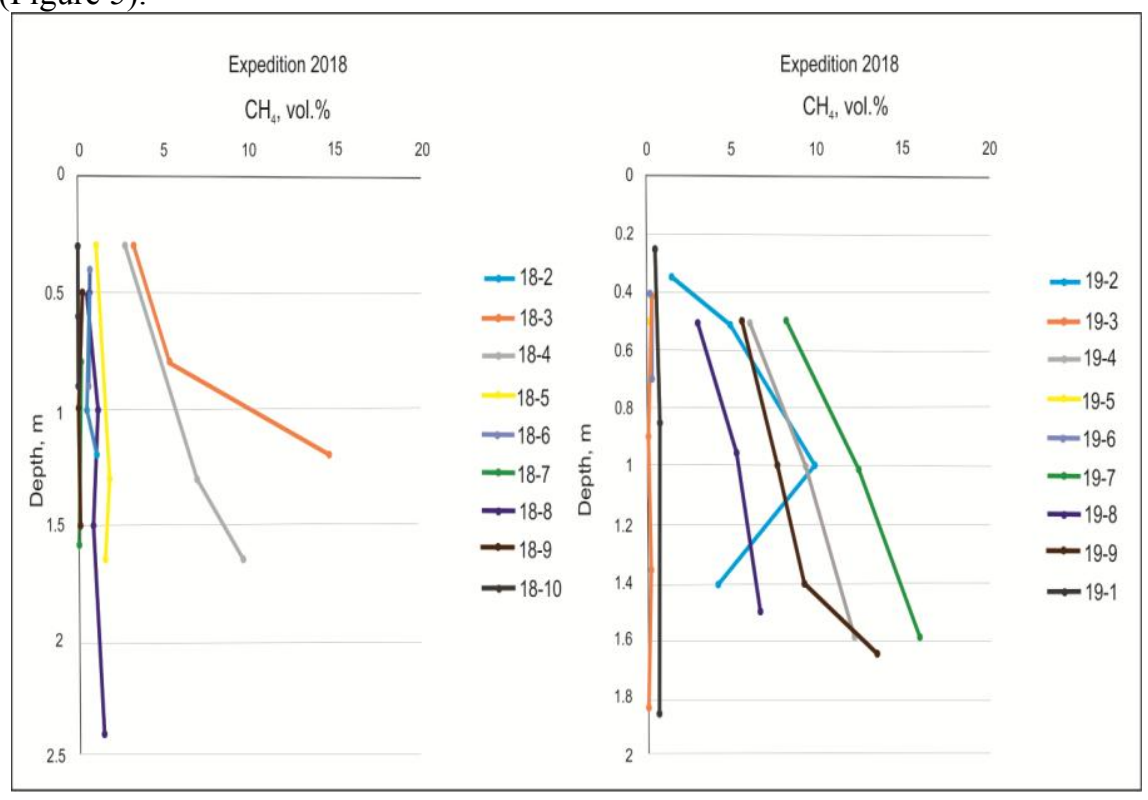

Fig. 5. Distribution of methane concentration with depth at different sites.

Maximal methane concentrations in the bottom sediments (above 1.5 vol.\%) were recorded in the samples from stations 19-2, 19-4, 19-7, 19-8, 19-9, 18-3, 18-4. Methane homologues (up to $\mathrm{C}_{4} \mathrm{H}_{10}$ ), as well as unsaturated $\mathrm{HC}$ gases, were detected in the same stations. Their content is rather small, dry gas coefficient $\mathrm{C}_{1} / \mathrm{C}_{2+}>2000$. The content of unsa- 
turated HCs in the sediments exceeds the content of the saturated ones, which indicates the predominant microbial process of gas formation. This is also evidenced by a direct correlation between the concentrations of methane and carbon dioxide, which corresponds to the activation of methane-generating bacteria in the sediments, alongside with methaneoxidizing microorganisms. At that, an increase in the proportion of the first the content of others increases alongside with their biomass and vital products increase (Figure 6).

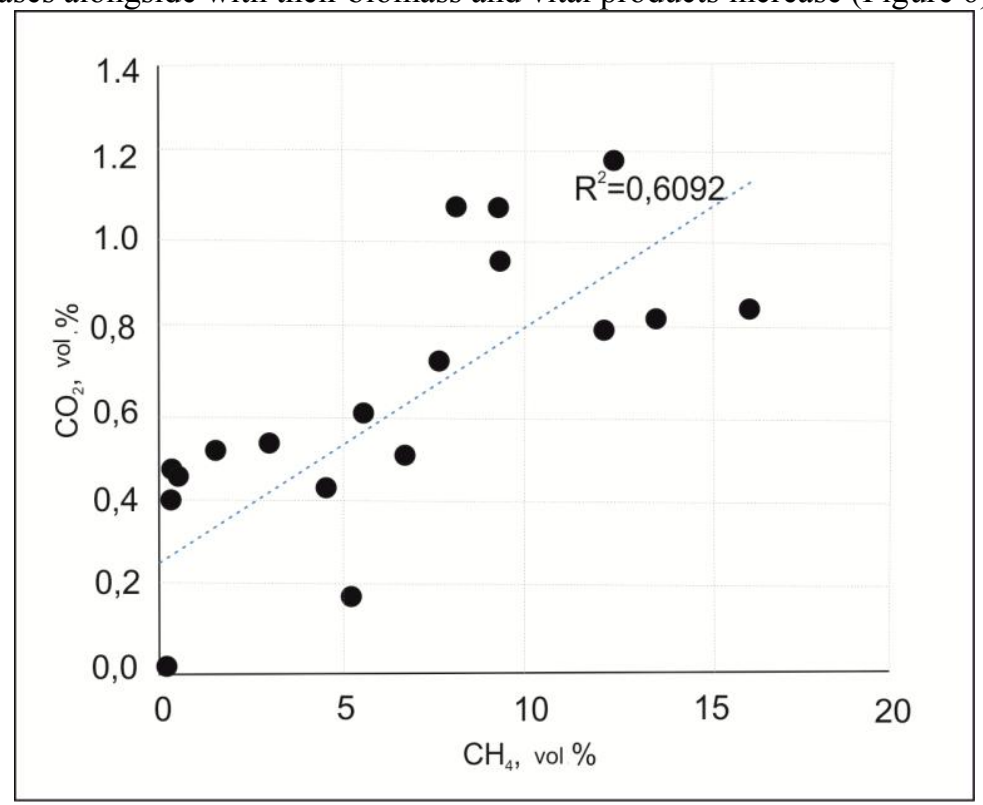

Fig. 6. Correlation of carbon dioxide and methane content in the sediments of Lake Onega.

The samples also revealed a high content of nitrogen and oxygen. A Predominantly high content of these gases is explained by the gas mixture with air (while degassing by the "Head space" analysis), while a significant decrease in the oxygen content (1.6-14.5\%, average $5.5 \%$, compared to $20.94 \%$ in air) and an increase in nitrogen content $(81-95 \%$ in most samples, average $90.5 \%$, compared to $78.08 \%$ in air), which indicates a different source of nitrogen alongside from the HC gases. Increased content of nitrogen could be explained by the generation of significant amounts of nitrogen by communities of microorganisms in sediments of freshwater sedimentation basins.

The highest bitumen content (up to $0.001 \%$ in the sediment) is determined at stations $19-7,19-8,19-9,18-4$ and 18-5. The main amount of samples is characterized by very low bitumen content (less than $0.0003 \%$ in the sediment). The extract is represented by light to oily groups, which is typical for recent sediments with a predominantly in-situ component of the organic matter.

\section{Conclusions}

The fulfilled studies indicate that the phenomena of gas saturation of the bottom sediments are often observed in Lake Onega. This mainly occurs in the mouths, while the degree of gas saturation in the sediments of the open part of the lake is incomparably less. At the same time, the origin of gases is not yet explained and should be studied in more detail. On the one hand, it is completely clear, based on the spatial confinement of gas-saturated sediments to enclosed areas, a significant part of them has a biogenic (microbial) origin. On the 
other hand, taking into account the structural confinement of the gulf bays, some of the gases may have a deep origin, as it was established in the Kandalaksha Bay, the White Sea.

The authors thank the crew of the R/V "Ecologist" throughout the entire research cycle, starting from 2016 who provided the opportunity for successful and fruitful work.

The studies were supported by the grant of the Russian Foundation for Basic Research No. 18-0500303.

\section{References}

1. A.E. Fersman Geochemical and mineralogical methods of minerals prospecting (in Russian). (Publishing House of the Academy of Sciences of the USSR, M. 1940)

2. V.A. Sokolov Direct geochemical methods of oil searches (in Russian). (Gosoptechizdat, M. 1947)

3. A.A. Kartsev, Z.A. Tabasaransky, M.I. Subbota, G.A. Mogilevsky Geochemical methods of prospecting and exploration of oil and gas fields (in Russian). (Gostoptekhizdat, M. 1954)

4. V.A. Uspenskyy Balance of carbon in biosphere (in Russian). 101 (Leningrad, 1956)

5. V.A. Sokolov The geochemistry of natural gases (in Russian). 293-320 (M.: Nedra, 1971)

6. E.V. Stadnik New direct methods of geochemical searches for oil and gas (in Russian). Oil and gas geology and geophysics, 7, 52 (VNIIOENG, 1984)

7. A.P. Solovov Geochemical methods of prospecting for mineral deposits (in Russian). (M.: Nedra, 1985)

8. E.M. Galimov Sources and mechanisms of formation of hydrocarbon gases in sedimentary rocks (in Russian). Geochemistry, 2, 163-180 (1989)

9. N.A. Voroshilov, S.A. Veshev, S.G. Alekseev, V.I. Vasilyeva Geochemical method of hydrocarbon searches (in Russian). (RF patent No. 1087796, 1996)

10. A.M. Vanisov, A.L. Klopov Features of gas-geochemical surveys in Western Siberia (in the complex of remote and geophysical methods of local oil forecasting) (in Russian). SCIENCE AND TECHNOLOGY. (EXPLORATION AND DEVELOPMENT, 2009)

11. R.B. Shakirov Gas-geochemical fields of the marginal seas of the Far East region: distribution, origin, connection with geological structures, gas hydrates and seismotectonics (in Russian). Dissertation for the degree of doctor of geology-mineral sciences, 459 p. (V.I.Ilichev Pacific Oceanology Institute, RAS, 2015)

12. A.E. Rybalko, M.Yu. Tokarev, D.A. Subetto, et al. New data on the structure of Lake Onega according to geological and geophysical research in 2016-2017 (in Russian). Proceedings of the VI International Scientific and Practical Conference "Marine Research and Education (MARESEDU-2017)", 254-256 (Tver: LLC "PolyPRESS", 2017)

13. M. I. Aleshin, S. G. Mironyuk, M. Yu. Tokarev, et al. First results of the study of the patches of Lake Onega (in Russian). Processes in geomedia, 1(14), 732-740 (2018)

14. A.E. Rybalko, D.A. Subetto, G.B. Fedorov, et al. First experience of geotechnical drilling in Lake Onega (in Russian). Proceedings of the VIII International Scientific and Practical Conference "Marine Research and Education (MARESEDU-2019)", 2(3), 94-97 (Tver: LLC "PolyPRESS", 2020) 